\title{
Pelapisan Hydroxyapatite Pada Logam Titanium Material Sistem Gas Buang Mesin Diesel Generator
}

\author{
Lilik Budiyanto \\ Universitas Maritim Amni Semarang \\ Email: Budiyantolilik@gmail.com
}

\begin{abstract}
ABSTRAK
Sistem gas buang pada diesel generator memerlukan material yang tahan panas.penggunaan logam titanium dirancang untuk material sistem gas buang. Sistem pelapisan material untuk aplikasi temperatur tinggi yang di kenal dengan Thermal Barrier Coating (TBC) telah di aplikasikan pada material mesin diesel. TBC memiliki kemampuan menurunkan temperatur pada permukaan dan melindungi oksidasi thermal pada saat temperatur tinggi. Pada penelitian ini membahas tentang pelapisan material keramik hydroxyapatite (HA) pada logam titanium yang akan digunakan sebagai material sistem gas buang dengan variasi temperatur pelapisan. Penelitian ini bertujuan untuk meningkatkan kualitas logam titanium sebelum di gunakan pada material sistem gas buang diesel generator agar lebih tahan panas karena paparan gas sisa pembakaran. Modifikasi logam titanium dengan pelapisan hydroxyapatite diperlukan karakteristik material dan temperature yang tepat untuk mengasilkan kerekatan pelapisan yang tinggi pada substart. Metode yang dilakukan adalah pengujian kandungan komposisi kimia pada logam titanium,pengujian mikroskop makro pada pelapisan keramik dan pengujian kerekatan dengan spesimen variabel suhu $700^{\circ} \mathrm{C}, 800^{\circ} \mathrm{C}$ dan $900^{\circ} \mathrm{C}$. Dengan pengujian yang telah peneliti lakukan pada spesimen dengan variasi temperatur pelapisan $900^{\circ} \mathrm{C}$ diketahui memiliki disfusi pada substrat dan memiliki nilai kerekatan paling tinggi dibanding dengan variabel yang lain.
\end{abstract}

Kata Kunci: thermal barrier coating, hydroxyapatite, titanium.

\section{PENDAHULUAN}

Mesin Diesel generator adalah mesin yang digunakan untuk membangkitkan listrik dengan sistem induksi elektro magnetik.Untuk menjamin ketersediaan listrik di atas kapal diesel generator harus beroperasi terus menerus secara bergantian (jj handoyo, 2014). Hal ini menyebabkan temperatur gas buang yang tinggi untuk itu di perlukan material yang kuat dan tahan panas.

Penelitian ini bertujuan untuk meningkatkan kualitas logam titanium sebelum di gunakan untuk material sistem gas buang diesel generator agar lebih tahan panas karena paparan gas sisa pembakaran. Modifikasi logam

https://doi.org/10.46484/db.v1i1.190 titanium (Ti) dengan pelapisan hydroxyapatite diperlukan karakteristik material dan temperatur yang tepat untuk mengasilkan kerekatan pelapisan yang tinggi pada substrat. Dengan pelapisan keramik hydroxyapatite pada logam titanium yang akan di gunakan sebagai material sistem gas buang diesel generator menjadi lebih tahan panas sehingga mampu meredam paparan gas sisa pembakaran.

Titanium merupakan material logam yang kuat. Dalam kondisi murni memilik kekuatan luluh mencapai 241 MPa dengan elongasi sebesar $55 \%$. Titik lebur dari logam ini adalah $1.677^{\circ} \mathrm{C}$. Titanium bukan konduktor yang baik jika dibandingkan dengan tembaga (Ezugwu, E.O. \& Wang, 
Z.M,1997). Pada penelitian sebelumnya material titanium digunakan untuk katalis knalpot sepeda motor dengan hasil penurunan emisi $\mathrm{CO}$ gas buang rata rata $18,93 \%$ (Yoga Arob Wicaksono, warju 2014).

Ada beberapa metode pelapisan keramik pada titanium. Di dunia industri teknik coating yang paling banyak digunakan saat ini adalah teknik Air Plasma Spray, tetapi memiliki biaya yang mahal sehingga Teknik yang digunakan pada penelitian ini untuk menghemat biaya adalah jenis coating Flame Spraying. Dimana Teknik ini merupakan teknik klasik, perkembangan antara 1910 dan 1920 secara luas menggunakan proses seperti flame sprayingdanwire arc spraying. Plasma spray, perkembangan di tahun 1970an, menggunakan temperatur tinggi plasma jet menghasilkan pancaran bunga api dengan temperatur lebih dari $150^{\circ} \mathrm{K}$, yang mana membuat material hasil spray mengeras seperti oxides dan molybdenum (Vishu Sankar, 2014)

\section{METODE}

\subsection{Bahan dan Alat}

Pada penelitian ini spesimen yang di gunakan adalah logam jenis titanium Ti-6Al-4V yang di potong persegi empat dengan ukuran $30 \mathrm{~mm} \mathrm{X}$ $40 \mathrm{~mm}$ tebal $5 \mathrm{~mm}$. Bahan pelapis menggunakan keramik jenis HA atau Hydroxyapatite keramik ini memiliki sifat biokompatibilitas yang bagus, karena secara kimia dan fisika memiliki kandungan mineral sama dengan tulang yang bisa menyerap panas dengan baik (Putri Arini, Ahmad Fadli, Amun Amri, 2016).

Alat yang digunakan untuk melakukan pelapisan adalah Thermal Barrier Coating (TBC). TBC memiliki kemampuan menurunkan temperatur pada permukaan dan melindungi oksidasi thermal pada saat temperatur tinggi.

\subsection{Prosedur Penelitian}

Variabel pelapisan keramik hydroxyapatite pada logam titanium menggunakan Thermal Barrier Coating dengan jarak $10 \mathrm{~cm} \pm 2 \mathrm{~cm}$ variable temperature $700^{\circ} \mathrm{C}, 800^{\circ} \mathrm{C}$ dan $900^{\circ} \mathrm{C}$, prosedur penelitian memiliki beberapa tahap yaitu persiapan pembuatan spesimen, persiapan substrat, proses pelapisan keramik dan karakterisasi spesimen.

Pada tahap persiapan: Serbuk hidroxiapatite (HA) ditakar dan dimasukan dalam botol yang akan di pasang pada flame spray dengan berat serbuk 25 gram. kemudian botol yang sudah terisi dengan serbuk HA dipasang kembali pada flame Spray.

Pada tahap persiapan substrat, sediakan logam titanium yang masih dalam bentuk plat dengan tebal $5 \mathrm{~mm}$ perlu kita potong dahulu sebelum kita lapisi keramik dengan metode TBC, dalam hal ini penulis memotong benda kerja tersebut dengan ukuran $30 \mathrm{mmX}$ $40 \mathrm{~mm}$ agar memudahkan kita dalam melakukan pelapisan.

Pada tahap pelapisan spesimen titanium yang sudah di potong dan di bersihkan, menaruh benda kerja (titanium) yang sudah dipotong, diamplas dan di bersihkan pada meja besi, menyalakan flame spray dengan pematik kemudian atur pada pengatur oksigen dan asetelin untuk mencapai titik nyala yang tepat. Memanaskan benda kerja titanium sampai titik panas 3 varibel pada 3 spesimen yaitu kurang lebih $700^{\circ} \mathrm{C}, 800^{\circ} \mathrm{C}, 9000^{\circ} \mathrm{C} \pm 5^{\circ} \mathrm{C}$ dengan menggunakan thermo gun kita bisa melihat suhu yang telah dicapai pada benda kerja.

Pemanasan yang dilakukan pada langkah ini peneliti membuat 3 variabel untuk mencari temperatur yang tepat dalam pelapisan keramik tersebut. Pemanasan ini berfungsi untuk membuka pori-pori logam titanium agar 
bubuk keramik hydroxyapatite bisa masuk ke dalam pori-pori logam titanium yang dilakukan pelapisan.

Tabel 1. Tabel uji komposisi kimia pada logam titanium.

\begin{tabular}{|c|c|c|}
\multirow{2}{*}{ UNSUR } & \multicolumn{2}{|c|}{ SAMPEL UJI } \\
\cline { 2 - 3 } & TEST 16/S1154 (\%) & Standart Doviasi \\
\hline Fe 2 & 91,77 & 0,0285 \\
\hline C & 0,000 & 0,0000 \\
\hline Si & 0,232 & 0,0005 \\
\hline Mn 1 & 2,55 & 0,0199 \\
\hline P & 0,007 & 0,0000 \\
\hline S & 0,006 & 0,0000 \\
\hline Cr 1 & 0,222 & 0,0027 \\
\hline Mo & 0,010 & 0,0000 \\
\hline Ni 1 & 4,85 & 0,0095 \\
\hline Al & 0,000 & 0,0000 \\
\hline B & 0,0000 & 0,0000 \\
\hline Co & 0,089 & 0,0005 \\
\hline Cu & 0,072 & 0,0000 \\
\hline Nb & 0,000 & 0,0000 \\
\hline Pb & 0,0000 & 0,0000 \\
\hline Sn & 0,000 & 0,0000 \\
\hline$\pi$ Ti & 0,016 & 0,0003 \\
\hline V & 0,006 & 0,0102 \\
\hline W & 0,000 & 0,0000 \\
\hline
\end{tabular}

Sumber tabel 1: laboratorium Logam Ceper Politeknik manufaktur Ceper

Pada tahap karakteristik titanium yang di lakukan pelapisan dengan hydroxyapatite menggunakan uji komposisi pada titanium untuk mengetahui komposisi kimia logam titanium. Uji XRD SEM untuk mengetahui untuk mengkaji morfologi kristal sedangkan pengujian microanalyser bertujuan untuk mengetahui komposisi kristal. Kajian morfologi adalah kajian yang meliputi kekasaran kristal, ukuran kristal, bentuk kristal, proses pengintian serta fenomena pembentukan kristal.

Uji mikroskop makro dipergunakan untuk melihat sisi permukaan antar muka pada lapisan untuk melihat difusi atau tidak hasil pelapisan HA yang dilakukan.

Serta pengujian kerekatan dimaksudkan untuk mengetahui tingkat kerekatan lapisan, sehingga di harapkan peneliti mengetahui sejauh mana kemampuan lapisan tidak mudah terkelupas dan sejauh mana daya rekat lapisan tersebut. Pada pengujian kerekatan yang peneliti lakukan menggunakan standar ASTM D 339509.

\section{HASIL DAN PEMBAHASAN 3.1 Hasil Penelitian}

Pada penelitian ini di lakukan coating HA pada logam titanium dengan metode thermal barrier coating. Terdapat 3 sampel coating yang di variasikan menurut temperatur pelapisan $700^{\circ} \mathrm{C}, 800^{\circ} \mathrm{C}, 900^{\circ} \mathrm{C}$. Tabel 1 menunjukan kandugan komposisi sampel logam titanium di tabel bisa dilihat bahwa kandungan $\mathrm{Ti}$ hanya $0,016 \%$, kandungan $\mathrm{Al}=0,000 \%$, kandungan $\mathrm{V}=0,006 \%$ dan paling banyak kandungannya adalah $\mathrm{Fe} 2=$ 91,77\%. Hasil pengujian komposisi di ketahui bahwa logam spesimen mengandung Titanium dengan kandungan $0,016 \%$.

\subsection{Analisis Uji Scaning Electron Microscope (SEM)}

Pada masing-masing spesimen terbentuk gumpalan atau aglomerat. Terjadinya gumpalan atau Aglomerat butiran HA karena coupling agent vinyl silane menyelimuti butiran HA (Dian A, Suasmoro 2014), hal itu ditunjukan pada gambar lingkaran masing-masing spesimen di pengujian SEM. Untuk menunjukan perbedaan bentuk dan mempermudah analisis ketiga spesimen.
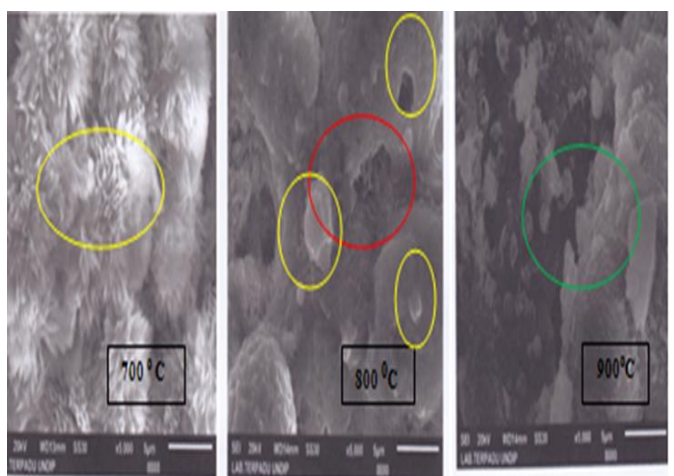

Gambar 1. Uji SEM tiga variabel $700^{\circ} \mathrm{C}, 800^{\circ} \mathrm{C}$ dan $900^{\circ} \mathrm{C}$ dengan perbesaran 5000 kali.

Pada gambar 1 Dari ketiga spesimen yang diuji Scaning Electron 
Miscroscope (SEM) menunjukkan persamaan mengenai daerah persebaran unsur karbon, daerah berwarna gelap merupakan daerah persebaran senyawa karbon sedangkan aglomerat atau gumpalan berwarna putih adalah lapisan Hidroxiapatite. Dari ketiga spesimen tersebut menunjukan perbedaan temperatur mempengaruhi unsur karbon dan pada lapisan semakin tinggi temperatur memungkinkan untuk melapiskan butiran hidroxiapatite, pada permukaan spesiman yang dapat dilihat pada hasil pengujian Scaning Electron Miscroscope (SEM) pada temperatur $800^{\circ} \mathrm{C}$ dan $900^{\circ} \mathrm{C}$ terlihat lapisan $\mathrm{HA}$ tidak merata dan terdapat lubang poripori pada lapisan.

\subsection{Analisis Uji Makro}

Pengujian dilakukan pada sisi samping pelapisan dengan membersihkan sisi samping lebih dahulu untuk melihat substart dan pelapisannya dengan pembesaran 50 kali. Selain untuk melihat interface antar muka pengujian ini dimaksudkan juga untuk mengukur ketebalan pelapisan dari ketiga spesimen tersebut.

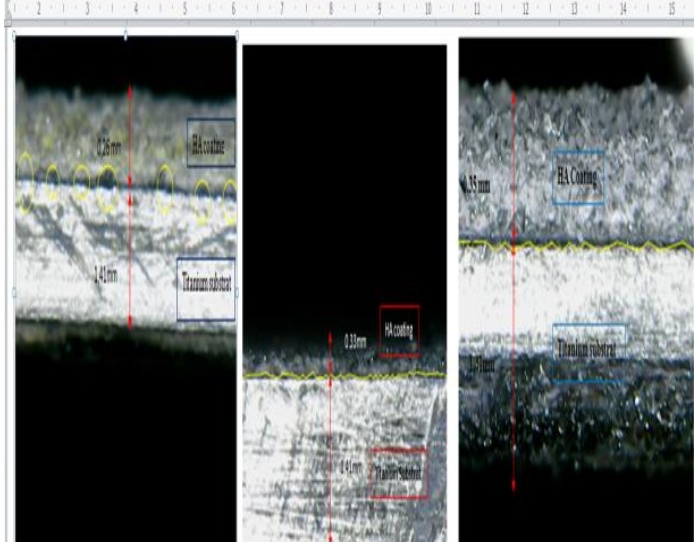

Gambar 2. Hasil uji mikrsokop makro ke tiga spesimen

Hasil uji mikroskop makro dapat menunjukan bahwa semakin tinggi temperatur lapisan semakin dalam difusi lapisan tersebut. Terdapat hubungan antara pengujian mikroskop makro dan pengujian SEM bahwa kedua pengujian tersebut sama-sama menunjukan pada temperatur yang paling tinggi yaitu $900^{\circ} \mathrm{C}$ menghasilkan hasil uji yang paling baik. Semakin tinggi temperatur pelapisan semakin merata pelapisan dan memiliki difusi yang semakin dalam. Kedua pengujian tersebut akan diperkuat pada pengujian kerekatan.

\subsection{Analisis Uji Kerekatan}

Pada pengujian kerekatan yang peneliti lakukan menggunakan standar ASTM D 3395-09. Pengujian kerekatan dilakukan pada tiga spesimen yaitu: spesimen pertama variabel temperatur $700^{\circ} \mathrm{C}$ dengan ketebalan lapisan $260 \mu \mathrm{m}$, spesimen ke dua variabel temperatur $800^{\circ} \mathrm{C}$ dengan ketebalan lapisan $330 \mu \mathrm{m}$ dan spesimen ketiga variabel temperatur $900^{\circ} \mathrm{C}$ dengan ketebalan lapisan 350 $\mu \mathrm{m}$.

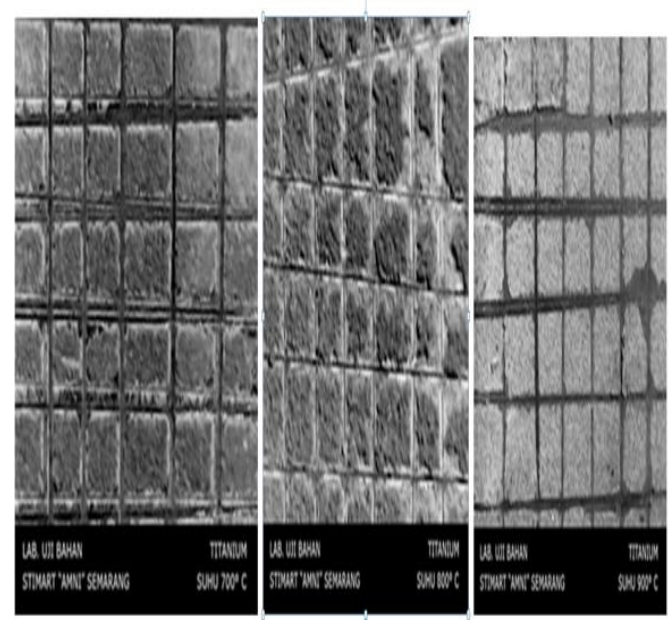

Gambar 3. hasil uji kerekatan ketiga spesimen

Tingkat kerekatan pelapisan dipengaruhi beberapa faktor salah satunya adalah Variabel temperatur semakin tinggi tempertur semakin tinggi pula tingkat kerekatan pada pelapisan (sudarmono 2013). Dari ketiga spesimen dapat diperbandingkan bahwa spesimen dengan variabel temperatur $900^{\circ} \mathrm{C}$ memiliki daya rekat atau addesive yang paling tinggi dengan nilai pengelupasan $5 \%$ dan kelas 4B dibanding dengan variabel temperatur $700^{\circ} \mathrm{C}$ dan $800^{\circ} \mathrm{C}$ 
Dengan terdifusinya serbuk secara baik seperti pada spesimen dengan temperatur pelapisan $800^{\circ} \mathrm{C}$ dan $900^{\circ} \mathrm{C}$, material hydroxyapatite dapat masuk kedalam substrat secara merata

\section{SIMPULAN}

Dari hasil penelitian dapat disimpulkan sebagai berikut: Komposisi logam titanium yang di jadikan sebagai substrat merupakan logam jenis titanium paduan yang bisa digunakan untuk material sistem gas buang diesel generator.

Dari hasil analisis pengujian SEM, Pengujian mikroskop makro dan pengujian kerekatan dapat diambil analisis bahwa spesimen semakin tinggi temperatur pelapisan semakin dalam lapisan HA masuk ke dalam pori pori substrat sehingga memiliki tingkat kerekatan yang paling baik dengan area pengelupasan 5\% masuk kelas 4B.

Dari hasil analisis pengujian di ketahui peningkatan kualitas logam titanium yang digunakan untuk material sistem gas buang diesel generator dengan pelapisan hydroxyapatite menggunakan thermal barrier coating sebaiknya menggunakan temperatur $900^{\circ} \mathrm{C}$.

Saran dari peneliti variabel ini bisa di teliti dengan variabel temperatur yang berbeda.

Penelitian ini dapat dilanjutkan dengan pengujian konduktifitas thermal untuk mengetahui nilai resistant (Hariyati P, Sulistijono 2010) yang dihasilkan dari proses pelapisan keramik hydroxyapatite terhadap panas gas buang mesin diesel generator.

\section{DAFTAR PUSTAKA}

Dian Agustinawati, Suasmoro (2014) Analisa XRD dan SEM pada dan hasilnya mempunyai addesive yang baik dibandingkan dengan spesimen yang lain. Pelapisan menghasilkan pencapaian adhesi yang baik apabila pelapis masuk ke substrat. Lapisan Tipis TiC Setelah Uji Oksidasi, Jurnal Teknik vol. 3, No. 2.

Ezugwu, E.O. \& Wang, Z.M., (1997), "Titanium alloys and their machinability- a review", Journal of Materials Processing Technology, 262-274.

Hariyati P, Sulistijono, Lukman N, Rindang F, Cartha K, (2010) Studi Antar Muka Top Coat Dan Bond Coat Pada Rekayasa Pelapisan Alumina Sebagai Lapisan Perintang Panas Untuk Aplikasi Temperatur Tinggi, Mekanika jurnal, Volume 9 .

Jusak Johan Handoyo (2014), Teknik Kelistrikan Kapal Ahli Teknik Tingkat III.

Putri Arini ,Ahmad Fadli, Amun Amri (2016) Coating Hidroksiapatit Pada Logam Stainless Steel 316L Menggunakan Metode DIP Coating Dengan Variabel Temperatur Sintering Dan Komposisi Air Dalam Suspensi, Volume 3.

Sudarmono Rizki Yulianto, Edi Widodo.(2013), Analisa Pengaruh Variasi Temperatur Proses Pelapisan Nikel Khrom Terhadap kualitas ketebalan Dan Kekerasan Pada Baja ST 40, Proceding Call For Paper-SNFT UMSIDA, 145149.

Vishu Sankar (2014). Thermal Barrier Coating Material Selection, Method Of Prepare And AReview. Internatioanl Journal Mech Eng; Vol 3, No 2,510-517. 
Yoga Arob Wicaksono, warju (2014) Pengaruh Catalytic Converter Titanium Dioksida Terhadap Emisi Gas Buang Sepeda Motor Honda Supra X 125 Volume 03 Nomor 02, 197-206. 